\title{
Arginine and aerobic training prevent endothelial and metabolic alterations in rats at high risk for the development of the metabolic syndrome
}

\author{
Renata F. Medeiros ${ }^{1 *}$, Thaiane G. Gaique ${ }^{1}$, Thais Bento-Bernardes ${ }^{1}$, Raquel Kindlovits ${ }^{1}$, \\ Tamiris M. B. Gomes ${ }^{1}$, Nadia Alice V. Motta ${ }^{1}$, Fernanda Carla Brito ${ }^{1}$, Caroline Fernandes-Santos ${ }^{2}$, \\ Karen J. Oliveira ${ }^{1}$ and Antonio Claudio L. Nóbrega ${ }^{1}$ \\ ${ }^{1}$ Department of Physiology and Pharmacology, Fluminense Federal University, 24210-130 Niterói, Rio de Janeiro, Brazil \\ ${ }^{2}$ Department of Basic Science, Fluminense Federal University, 28625-650 Nova Friburgo, Rio de Janeiro, Brazil
}

(Submitted 9 December 2016 - Final revision received 7 June 2017 - Accepted 12 June 2017)

\section{Abstract}

Endothelial function is a key mechanism in the development of CVD. Arginine and exercise are important non-pharmacological strategies for mitigating the impact of metabolic changes in the metabolic syndrome, but the effect of their combined administration is unknown. Thus, the aim of this study was to investigate the isolated and combined effects of aerobic training and arginine supplementation on metabolic variables and vascular reactivity in rats at high risk for developing the metabolic syndrome. Wistar rats were divided into two groups: control and fructose (F - water with $10 \%$ fructose). After 2 weeks, the F group was divided into four groups: $\mathrm{F}$, fructose + arginine (FA, $880 \mathrm{mg} / \mathrm{kg}$ per d of L-arginine), fructose + training (FT) and fructose + arginine + training (FTA); treatments lasted for 8 weeks, and no difference was observed in body mass gain. Arginine did not improve the body protein content, and both the FA and FT groups show a reversal of the increase in adipose tissue. Insulin increase was prevented by training and arginine, without additive effect, and the increase in serum TAG was prevented only by training. The F group showed impaired endothelium-dependent vasodilation and hyperreactivity to phenylephrine, but arginine and training were capable of preventing these effects, even separately. Higher nitric oxide level was observed in the FA and FT groups, and no potentiating effect was detected. Thus, only training was able to prevent the increase in TAG and improve the protein mass, and training and arginine exert similar effects on fat content, insulin and endothelial function, but these effects are not additive.

Key words: Metabolic syndrome: Fructose: Aerobic training: Arginine supplementation

CVD is a major cause of death worldwide ${ }^{(1)}$. Therefore, understanding the pathophysiology of CVD and developing strategies to minimise its appearance in the population have become of paramount importance ${ }^{(2)}$. In fact, some conferences had attempted to examine and propose strategies for identifying highrisk cardiovascular patients who require primary prevention ${ }^{(3-5)}$.

The elevated incidence of CVD is believed to be partially due to the modern lifestyle ${ }^{(2)}$. Diet has changed on a global scale, and the emphasis on fructose consumption has increased in recent decades. In addition, high fructose consumption has been correlated to the onset of cardiometabolic alterations in the world's population ${ }^{(6)}$. Chronic fructose ingestion has been used as a model of $\mathrm{CVD}^{(7)}$, and this model can be characterised by increased serum insulin and TAG levels, as well as vascular disorders ${ }^{(8-10)}$

Because of the elevated prevalence of CVD, some researchers are dedicated to the evaluation and prevention of cardiovascular risk factors in different ethnic groups, and it has been observed that metabolic alterations are emerging earlier in life ${ }^{(11)}$. In this context, non-pharmacological treatment might be considered an important intervention for avoiding the appearance and progression of CVD because it usually has a low cost ${ }^{(12)}$. Considering the above information, understanding the mechanisms underlying how non-pharmacological treatment might benefit a population that shows subclinical alterations and is at a constant risk of developing CVD might be crucial to decreasing the incidence of such diseases.

It is worth noting that the endothelium has been considered crucial to the regulation of vascular homoeostasis ${ }^{(13)}$; therefore, endothelial cell dysfunction could precede the development of atherosclerotic and morphological changes. In addition, endothelial changes contribute to the development of late clinical complications $^{(14)}$, including arterial remodelling and abnormal angiogenesis $^{(15-17)}$.

L-Arginine, a semi-essential amino acid, is the precursor of nitric oxide (NO) production via endothelial nitric oxide synthase (eNOS). NO activates smooth muscle soluble guanylate cyclase and thereby increases the cyclic GMP (cGMP) and decreases the intracellular $\mathrm{Ca}^{2+}$ concentrations, culminating in the relaxation of smooth muscle cells and the inhibition of platelet aggregation ${ }^{(18)}$. Because arginine is a substrate for eNOS and NO is crucial for endothelial health, a number of 
early experiments using animal models and humans investigated the potential efficacy of arginine supplementation in reversing endothelial dysfunction in pathological states ${ }^{(19-24)}$. A research group showed that acute intravenous ${ }^{(19)}$ and chronic oral arginine ingestion ${ }^{(20)}$ in rabbits reverses the vascular damage caused by a hypercholesterolaemic diet. In humans, the results are controversial because some studies have shown an improvement in the endothelial function of individuals with existing endothelial damage, primarily in the elderly population $^{(21,22)}$, but in healthy patients oral arginine supplementation at the same dose does not improve endothelial function $^{(23,24)}$. Thus, whether arginine supplementation would modulate metabolic variables and vasodilation in healthy subjects who present with metabolic alterations but do not have the established disease remains unknown.

Regular aerobic exercise is widely recognised as a non-pharmacological approach to reduce CVD morbidity and mortality ${ }^{(25,26)}$. In recent years, several researchers have studied the mechanisms that explain the beneficial health effects of regular exercise and have shown that exercise decreases TAG, increases HDL cholesterol ${ }^{(27)}$, lowers blood pressure ${ }^{(28)}$, improves glucose metabolism and insulin sensitivity ${ }^{(29)}$ and reduces body weight and inflammatory markers ${ }^{(30)}$. These risk factor improvements can explain nearly $59 \%$ of the reduction in $\mathrm{CVD}^{(31)}$. However, other mechanisms, such as improving endothelial function and NO bioavailability ${ }^{(32)}$ and enhancing vagal tone ${ }^{(33)}$, might be involved in the negative correlation between chronic physical activity and CVD incidence.

Some mechanisms, such as decreases in the total peripheral resistance $^{(34)}$ and sympathetic nervous activity ${ }^{(35)}$ and increases in the bioavailability of $\mathrm{NO}^{(36)}$, could underlie the effect of arginine and training on CVD, but whether aerobic training and arginine supplementation have similar or additive effects in preventing CVD onset in individuals who are continuously exposed to a CVD-causing agent remains unknown. Thus, the aims of this study were to compare the effects of aerobic training and chronic arginine supplementation and investigate whether they exert similar or potentiating effects on metabolic variables and vascular reactivity in rats at high risk for developing the metabolic syndrome.

\section{Methods \\ Experimental design}

The handling and experimental protocols were approved by the Ethics Committee for the Care and Use of Laboratory Animals of Fluminense Federal University (Protocol 466/2013) and complied with the ethical guidelines of the Brazilian Society of Laboratory Animal Science. The experiments were performed on 2-month-old male Wistar rats ( $n$ 7/group; 329.9 (SEM 8.9) g), and the experimental model has been previously described by our group ${ }^{(7)}$. The animals were maintained under controlled temperature conditions $\left(24 \pm 1^{\circ} \mathrm{C}\right)$ on a 12 -h light cycle (lights on at 07.00 hours).

The animals were initially randomly allocated into two groups: a control $(\mathrm{C})$ group that received water and commercial chow (Nuvilab Cr- $1^{\circledR}$, Nuvital Nutrientes S/A; Table 1)
Table 1. Nutritional information of the Nuvilab $\mathrm{Cr}-1$ commercial chow*

\begin{tabular}{lrr}
\hline Nutritional informations & $1 \mathrm{~kg}$ of chow & $\%$ \\
\hline Energy content $(\mathrm{kJ})$ & 14058.0 & - \\
Energy content (kcal) & 3360.0 & - \\
Carbohydrates $(\mathrm{g})$ & 530.0 & 63 \\
Proteins $(\mathrm{g})$ & 220.0 & 26 \\
Lipids $(\mathrm{g})$ & 40.0 & 11 \\
Ash $(\mathrm{g})$ & 90.0 &
\end{tabular}

* Ingredients: ground whole maize, soya bean meal, wheat bran, calcium carbonate, dicalcium phosphate, sodium chloride, vitamins $A, D_{3}, E, K_{2}, B_{1}, B_{6}$ and $B_{12}$, niacin, calcium pantothenate, folic acid, biotin, chloride choline, iron sulphate, manganese monoxide, zinc oxide, calcium sulphate, sodium selenite, cobalt sulphate, lysine, methionine and butylatedhydroxytoluene. The nutritional information and ingredient composition were obtained from the chow label forNuvilab $\mathrm{Cr}-1$ (Nuvital Nutrientes S/A).

ad libitum for 2 weeks and a fructose group that received an overload of $10 \%$ D-fructose (Sigma-Aldrich) in drinking water ad libitum and commercial chow for 2 weeks (Fig.1). After 2 weeks, seven animals from each group were euthanised, and the remaining animals from the $C$ group $(n$ 7) were maintained under the same previously described conditions for an additional 8 weeks. The rats from the $\mathrm{F}$ group were divided into four sub-groups, all of which continued receiving D-fructose in their drinking water for an additional 8 weeks. The fructose + arginine (FA) group received $880 \mathrm{mg} / \mathrm{kg}$ per $\mathrm{d}$ of arginine (Sigma-Aldrich) by orogastric gavage. The fructose + training (FT) group was subjected to aerobic exercise training, and the fructose + training + arginine (FTA) group was subjected to a combination of aerobic training with arginine supplementation. The arginine dose was calculated according to the formula for dose translation based on the body surface area ${ }^{(37)}$, which was considered to equal $10 \mathrm{~g}$ for an adult person ${ }^{(38)}$. In this context, it is important to note that this amino acid is naturally found in human nutrition, specifically in edible mushrooms ${ }^{(39)}$ and in various meats, such as beef, pork and poultry ${ }^{(40)}$. The energy intake was assessed twice weekly and calculated by considering that $1.0 \mathrm{~g}$ of chow corresponds to $14.06 \mathrm{~kJ}(3.36 \mathrm{kcal})$ and $1.0 \mathrm{~g}$ of fructose corresponds to $16.7 \mathrm{~kJ}(4.0 \mathrm{kcal})$.

\section{Aerobic exercise protocol}

Before initiating the experimental protocol, all animals were subjected to an adaptation period on a treadmill (Inbrasport ${ }^{\circledR}$ ) for 4 weeks $(5 \mathrm{~min} / \mathrm{d}$ with weekly increases of $0 \cdot 3-1.0 \mathrm{~km} / \mathrm{h}$ ). All of the animals underwent a maximal exercise test (MET) on a treadmill with an $11 \%$ inclination, an initial speed of $1.0 \mathrm{~km} / \mathrm{h}$ and increases in velocity of $0 \cdot 1 \mathrm{~km} / \mathrm{h}$ every 2 min. The MET was performed before the experiment, 2 weeks after the initiation of the experiment and at the end of the experiment to determine the maximum running speed ${ }^{(7)}$.

The groups assigned to aerobic training were subjected to a moderate-intensity exercise training regimen $(50-75 \%$ maximal running speed) with a $0-7 \%$ inclination on a treadmill $4 \mathrm{~d}$ /week during the last 8 weeks of the experimental $\operatorname{protocol}^{(7)}$. All of the animals allocated to the sedentary groups were subjected to $5 \mathrm{~min}$ in the treadmill at low intensity $(0.3 \mathrm{~km} / \mathrm{h})$ once a week to maintain their adaptation to the treadmill. 


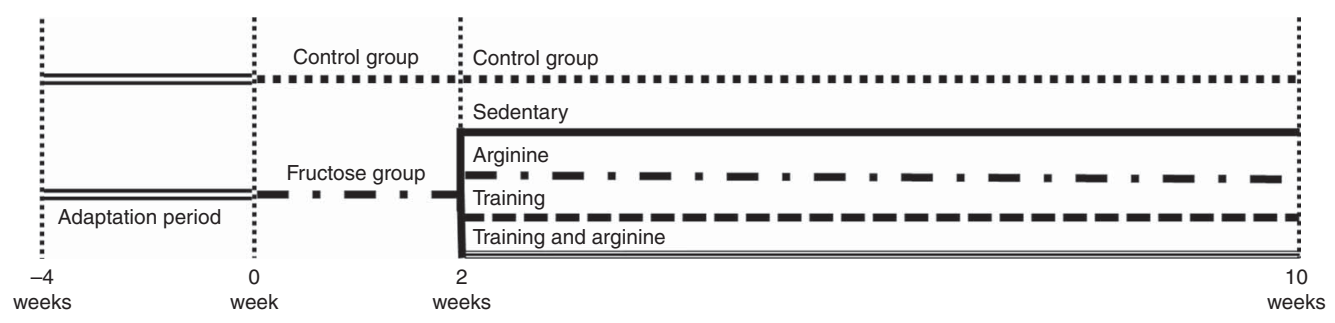

Fig. 1. Experimental protocol.

\section{Biochemical analysis}

Glycaemia (Accu-Chek glucometer; Roche Diagnostics) and serum TAG (enzymatic kit; Labtest) were measured in blood collected from the tail after $5 \mathrm{~h}$ of fasting, during which the animals received only tap water ad libitum. Subsequently, the animals were euthanised, and blood was collected by cardiac puncture from the right atrium, centrifuged for $15 \mathrm{~min}$ at $1700 \mathrm{~g}$ and $4^{\circ} \mathrm{C}$ to separate the serum and stored at $-80^{\circ} \mathrm{C}$ for future analysis.

The serum insulin was measured by ELISA (Cayman Chemical Company) ${ }^{(41)}$ at the end of the protocol. The serum NO levels were measured for the assessment of the nitrite content using an ozone-based chemiluminescence assay with an NO analyzer (Sievers Model 280 Nitric Oxide Analyzer; GE Healthcare), as previously described ${ }^{(42)}$.

\section{Body composition}

After euthanasia, the eviscerated carcasses were frozen at $-20^{\circ} \mathrm{C}$ for posterior analyses. The body fat and protein content were determined using the carcass technique ${ }^{(43)}$. In brief, the eviscerated carcasses were weighed, autoclaved and homogenised in distilled water (1:1). Aliquots of the homogenate were used to measure the protein and fat contents. The homogenate was used to gravimetrically determine the fat mass. The samples were hydrolysed in a shaking water bath at $70^{\circ} \mathrm{C}$ for $2 \mathrm{~h}$ with $30 \% \mathrm{KOH}$ in ethanol. After the addition of $9 \mathrm{M}$ sulphuric acid, the total lipids were extracted through three successive washes with petroleum diethyl ether. The samples were dried at room temperature until a constant weight was obtained. The protein from the homogenates was extracted at $37^{\circ} \mathrm{C}$ for $1 \mathrm{~h}$ using $0.6 \mathrm{~N} \mathrm{KOH}$. The samples were then centrifuged at $800 \mathrm{~g}$ and room temperature for $10 \mathrm{~min}$, and the supernatant was collected to measure the protein concentration using a Pierce ${ }^{\mathrm{TM}}$ BCA Protein Assay Kit (Thermo Fisher Scientific). The results are expressed as grams of fat or protein per $100 \mathrm{~g}$ of carcass.

\section{Vascular reactivity}

The vascular reactivity was assessed as previously described ${ }^{(7,44)}$. In brief, the thoracic aorta was dissected after 2 and 10 weeks of the experimental protocol and prepared for isometric tension recording. The aortas were placed in freshly prepared Krebs solution containing $119.0 \mathrm{~mm} \mathrm{NaCl}, 14.9 \mathrm{~mm} \mathrm{NaHCO}_{3}, 11.5 \mathrm{~mm}$ glucose, $4.7 \mathrm{~mm} \mathrm{KCl}, 4.2 \mathrm{~mm} \mathrm{KH}_{2} \mathrm{PO}_{4}, 1.2 \mathrm{~mm} \mathrm{MgSO}_{4}$ and $1.6 \mathrm{~mm}$ $\mathrm{CaCl}_{2}$. The aortas were cleaned, separated from adherent tissue and cut into rings with a diameter of approximately $3 \mathrm{~mm}$. Each ring was suspended between two wire hooks, mounted in 4-ml organ chambers with Krebs solution at $37^{\circ} \mathrm{C}$ and $\mathrm{pH} 7.4$ and continuously aerated with a mixture of $95 \% \mathrm{O}_{2}$ and $5 \% \mathrm{CO}_{2}$ under a resting tension of $1.0 \mathrm{~g}$.

The isometric tension of the tissues was recorded using a force-displacement transducer (Ugo Basile) controlled by software (Data Capsule Digital Recorder 17400; Ugo Basile). After a 1-h stabilisation period, the intact endothelium aortic rings were pre-contracted with phenylephrine ( $1 \mathrm{~mm}$ ), and the cumulative concentration-response curves of the aortic rings to acetylcholine $\left(10^{-9}-10^{-4} \mathrm{M}\right)$ were obtained. The relaxation curves are expressed as percent changes from the contraction induced by phenylephrine. The cumulative concentration-response curves to phenylephrine $\left(10^{-9}-10^{-4} \mathrm{M}\right)$ were also determined ${ }^{(44)}$.

\section{Quantitative histopathology}

At the moment of euthanasia, which was performed immediately after blood collection, samples of the thoracic aorta were immersed in $4 \%$ phosphate-buffered formalin ( $\mathrm{pH} 7 \cdot 2$ ) for $48 \mathrm{~h}$. After fixation, the samples underwent routine histology processing and were embedded in Paraplast ${ }^{\circledR}$ plus (\#P3558; Sigma-Aldrich). Quantitative analyses were performed using morphometric tools ${ }^{(7)}$.

The aortic rings were sectioned at $3-\mu \mathrm{m}$ thickness and stained with haematoxylin-eosin. Four non-consecutive digital images were acquired per animal using the Evos XL Core system (Thermo Fisher Scientific) and were analysed using Image-Pro ${ }^{\circledR}$ Plus version 4.5 (Media Cybernetics). The intima-media thickness (IMT) was estimated by taking two manual measurements at positions $0^{\circ}$ and $90^{\circ}$ for each aorta ring with the line feature. The lumen diameter was assessed from four digital images by measuring the smallest and largest luminal diameters using the line feature. The above-mentioned parameters were used to assess the IMT:lumen ratio.

\section{Statistical analyses}

The appropriate sample size of seven animals per group was calculated using the vasodilation of the thoracic aorta under acetylcholine stimulation as the primary outcome and assuming an average difference of $5 \%$ (effect size) and an equal SD of $5 \%$. Both values were obtained from preliminary experiments by adjusting the power of the statistical test to 0.8 and the $\alpha$ error to 0.05 .

The data normality was verified using the Shapiro-Wilk test. The experimental groups were compared by one-way ANOVA 
followed by Student's-Newman-Keuls post hoc test, when appropriate. Nonparametric variables were logarithmically transformed before analysis. The results are expressed as the means with their standard errors of the mean, and differences were considered significant if $P<0.05$.

\section{Results}

As observed in Table 2, fructose overload and aerobic training and/or arginine treatment did not change the body mass gain. The analysis of the body composition through a study of the carcass content showed no change in protein content after 2 weeks of the protocol. However, the protein content was improved after 8 weeks of training compared with that of the untrained groups ( $\mathrm{C}, \mathrm{F}$ and $\mathrm{FA}$ groups), which shows that training, but not arginine, improves the body protein content. However, fructose overload, even when administered for a short period of 2 weeks, increased the body fat content, and both arginine and aerobic training reversed this adverse effect.

As demonstrated through the MET (Table 3), neither fructose overload nor arginine supplementation altered the exercise capacity, although the trained groups (FT and FTA) showed an improvement in the velocity achieved on the MET $(P<0.001)$. A period of 2 weeks of fructose overload increased the serum insulin (29\%; $P=0.046$ ), and this effect was sustained until the 10th week of the experiment $(144 \% ; P=0 \cdot 014)$. Aerobic training and arginine supplementation protected the serum

Table 2. Weight and body composition

(Mean values with their standard errors) insulin from increasing after fructose overload. Glycaemia was not altered by fructose intake or training. At the end of the protocol, fructose consumption increased the serum TAG by $91 \%(P<0.001)$, and only training inhibited this increase.

A period of 2 weeks of fructose overload had no effect on the vascular reactivity response to acetylcholine $(P=0.39)$ or phenylephrine $(P=0.09)$. However, 10 weeks of fructose supplementation impaired the endothelium-dependent relaxation response induced by acetylcholine (Fig. 2(a)) $\left(\mathrm{EC}_{50}=36 \cdot 37 \times 10^{-7}\right.$ (SEM $\left.9.61 \times 10^{-7}\right)$ M; $\quad P<0.0 ; \quad 71.27 \%$ ) compared with the $\mathrm{C}$ group $\left(\mathrm{EC}_{50}=3.13 \times 10^{-7}\left(\operatorname{SEM} 1.9 \times 10^{-7}\right) \mathrm{M}\right)$, and arginine $\left(\mathrm{EC}_{50}=0.93 \times 10^{-7}\left(\operatorname{SEM} 0.4 \times 10^{-7}\right) \mathrm{M}\right)$, training $\left(\mathrm{EC}_{50}=11.44 \times 10^{-7}\right.$ $\left.\left(\operatorname{SEM} 5.1 \times 10^{-7}\right) \mathrm{M}\right)$ and training plus arginine $\left(\mathrm{EC}_{50}=1.89 \times 10^{-7}\right.$ (SEM $0.68 \times 10^{-7}$ ) M) were capable of preventing this endothelial alteration because the values were similar to those of the $\mathrm{C}$ group, despite the constant intake of fructose. The analysis of the vasoconstrictory response (Fig. 2(b)) revealed that the $\mathrm{F}$ group $\left(\mathrm{EC}_{50}=2.43 \times 10^{-7}\left(\operatorname{SEM} 0.65 \times 10^{-7}\right) \mathrm{M}\right)$ showed a hyperreactivity contractile response $(P<0.01)$ to phenylephrine compared with the $\mathrm{C}$ group $\left(\mathrm{EC}_{50}=13.6 \times 10^{-7} \quad\left(\mathrm{SEM} 2.12 \times 10^{-7}\right) \mathrm{M}\right)$. This phenomenon was prevented by arginine $\left(\mathrm{EC}_{50}=4.56 \times 10^{-7}\right.$ $\left.\left(\operatorname{SEM} 0.78 \times 10^{-7}\right) \mathrm{M}\right)$, training $\left(\mathrm{EC}_{50}=7.99 \times 10^{-7}\left(\operatorname{SEM~} 1.5 \times 10^{-7}\right) \mathrm{M}\right)$ and training plus arginine $\left(\mathrm{EC}_{50}=9.22 \times 10^{-7}\left(\operatorname{SEM} 2.39 \times 10^{-7}\right) \mathrm{M}\right)$.

Fructose intake did not decrease the NO bioavailability ( $480 \cdot 6$ (sem 42.97) nm) (Fig. 3) compared with that detected in the C group $(445 \cdot 3(\operatorname{sem} 36 \cdot 27) \mathrm{nm})$. The treatment with arginine or training increased the NO serum levels $(P<0 \cdot 00$;

\begin{tabular}{|c|c|c|c|c|c|c|c|c|c|c|c|c|}
\hline \multirow[b]{2}{*}{ Variables } & \multirow[b]{2}{*}{ Weeks } & \multicolumn{2}{|c|}{ C } & \multicolumn{2}{|l|}{$\mathrm{F}$} & \multicolumn{2}{|c|}{ FA } & \multicolumn{2}{|c|}{ Fructose + training } & \multicolumn{2}{|c|}{ Fructose + training + arginine } & \multirow[b]{2}{*}{$P$} \\
\hline & & Mean & SEM & Mean & SEM & Mean & SEM & Mean & SEM & Mean & SEM & \\
\hline \multirow[t]{2}{*}{$\Delta$ Weight $(\mathrm{g})$} & 2 & 35.34 & 5.92 & 39.89 & $5 \cdot 51$ & & & & & & & 0.58 \\
\hline & 10 & $334.50^{\S}$ & 3.21 & $334 \cdot 30^{\S}$ & 3.08 & 311.70 & 15.09 & 332.90 & 11.34 & 336.00 & 11.74 & 0.19 \\
\hline \multirow[t]{2}{*}{ Body protein (\%) } & 2 & 11.57 & 1.62 & $12 \cdot 50$ & 1.73 & & & & & & & 0.70 \\
\hline & 10 & 10.46 & 1.23 & 10.54 & 0.61 & $9 \cdot 31$ & 0.69 & $16 \cdot 53^{\star \star \ddagger}$ & 1.66 & $16 \cdot 77^{\star \dagger \ddagger}$ & 0.87 & $<0.01$ \\
\hline \multirow[t]{2}{*}{ Body fat (\%) } & 2 & $5 \cdot 13$ & 0.70 & $8 \cdot 90^{\star}$ & 1.43 & & & & & & & 0.04 \\
\hline & 10 & $6 \cdot 80$ & 1.23 & $13 \cdot 61^{\star \S}$ & 1.70 & $8.70^{\dagger}$ & 0.91 & $7.63^{\dagger}$ & 1.52 & $8.67^{\dagger}$ & $2 \cdot 11$ & 0.03 \\
\hline
\end{tabular}

C group, control group; F group, fructose group; FA group, fructose + arginine group.

The body fat and body protein were assessed using the carcass method (see the 'Methods' section). Statistical analysis (one-way ANOVA and post hoc Student's-Newman-Keuls test): ${ }^{*} P<0.05 v$. the $\mathrm{C}$ group; $\dagger P<0.05 v$. the $\mathrm{F}$ group; $¥ P<0.05 \mathrm{v}$. the FA group; $\S P<0.05 v$. the same group 2 weeks later.

Table 3. Training and metabolic parameters

(Mean values with their standard errors)

\begin{tabular}{|c|c|c|c|c|c|c|c|c|c|c|c|c|}
\hline \multirow[b]{2}{*}{ Variables } & \multirow[b]{2}{*}{ Weeks } & \multicolumn{2}{|c|}{$\mathrm{C}$} & \multicolumn{2}{|c|}{$\mathrm{F}$} & \multicolumn{2}{|c|}{$\mathrm{FA}$} & \multicolumn{2}{|c|}{ Fructose + training } & \multicolumn{2}{|c|}{ Fructose + training + arginine } & \multirow[b]{2}{*}{$P$} \\
\hline & & Mean & SEM & Mean & SEM & Mean & SEM & Mean & SEM & Mean & SEM & \\
\hline \multirow[t]{2}{*}{$\Delta$ Velocity $(\mathrm{km} / \mathrm{h})$} & 2 & 0.00 & 0.04 & 0.02 & 0.07 & & & & & & & 0.778 \\
\hline & 10 & 0.02 & 0.09 & $-0.06^{\star \S}$ & 0.25 & -0.014 & 0.17 & $0.57^{\star \dagger \ddagger ~}$ & 0.12 & $0.57^{\star \dagger \ddagger}$ & 0.13 & $<0.001$ \\
\hline \multirow[t]{2}{*}{ Insulin (mmol/l) } & 2 & 0.06 & 0.001 & $0.08^{\star}$ & 0.008 & & & & & & & 0.046 \\
\hline & 10 & 0.09 & 0.009 & $0 \cdot 22^{\star \S}$ & 0.068 & 0.17 & 0.038 & 0.09 & 0.007 & 0.13 & 0.011 & 0.014 \\
\hline \multirow[t]{2}{*}{ Glucose (mmol/l) } & 2 & $5 \cdot 15$ & 0.11 & 4.92 & 0.16 & & & & & & & 0.280 \\
\hline & 10 & 4.99 & 0.08 & $5 \cdot 20$ & 0.17 & $5 \cdot 52$ & 0.15 & $5 \cdot 58$ & 0.22 & $5 \cdot 37$ & 0.19 & 0.637 \\
\hline \multirow[t]{3}{*}{ TAG (mmol/l) } & 2 & 3.64 & 0.43 & 4.58 & 0.44 & & & & & & & 0.154 \\
\hline & 10 & 4.63 & 0.84 & $8 \cdot 86^{\star \S}$ & 1.04 & $8 \cdot 36^{\star}$ & 1.57 & $4 \cdot 32^{\dagger \ddagger}$ & 0.48 & $3 \cdot 27^{\dagger \ddagger}$ & $1 \cdot 34$ & $<0.001$ \\
\hline & 10 & $6 \cdot 80$ & 1.23 & $13 \cdot 61^{\star \S}$ & $1 \cdot 70$ & $8 \cdot 70^{\dagger}$ & 0.91 & $7.63^{\dagger}$ & 1.52 & $8.67^{\dagger}$ & $2 \cdot 11$ & 0.03 \\
\hline
\end{tabular}

C group, control group; F group, fructose group; FA group, fructose + arginine group.

Statistical analysis (one-way ANOVA and post hoc Student's-Newman-Keuls test): * $P<0.05 v$. the $\mathrm{C}$ group, $† P<0.05 v$. the $\mathrm{F}$ group, $¥ P<0.05 v$. the FA group; $\S P<0.05 v$. the same group 2 weeks later. 

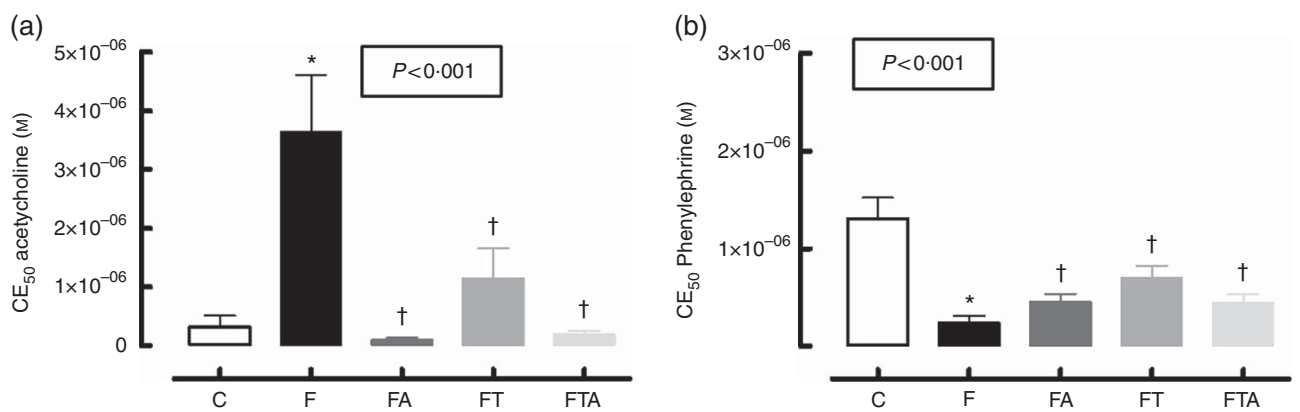

Fig. 2. Vascular reactivity response to acetylcholine (a) and to phenylephrine (b) after 10 weeks of fructose overload. Values are means with their standard errors represented by vertical bars. C group, control group; F group, fructose group; FA group, fructose + arginine group; FT group, fructose + training group; FTA group, fructose + training + arginine group; $\mathrm{CE}_{50}$, effective concentration needed to promote $50 \%$ of the maximum contractile effect. ${ }^{*} P<0.05 \mathrm{v}$. the $\mathrm{C}$ group; $\dagger P<0.05 \mathrm{~V}$. the $\mathrm{F}$ group.

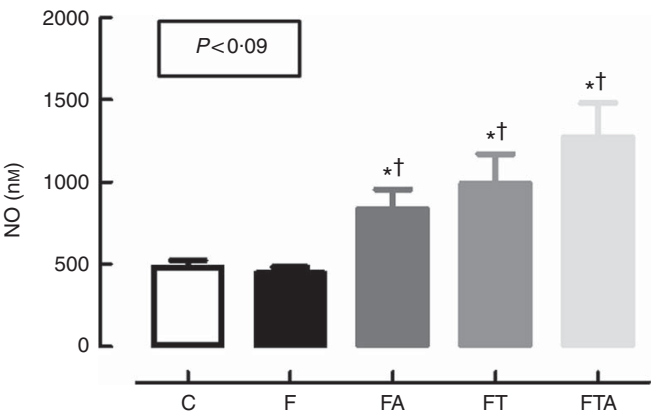

Fig. 3. Nitric oxide (NO) after 10 weeks of fructose overload. Values are means with their standard errors represented by vertical bars. C, control group; F group, fructose group; FA group, fructose + arginine group; FT group, fructose + training group; FTA group, fructose + training + arginine group. ${ }^{*} P<0.05 v$. the $C$ group; $\dagger P<0.05 v$. the $\mathrm{F}$ group

$\mathrm{FA}=838.8(\operatorname{sEM} 118 \cdot 0) \mathrm{nm} ; \mathrm{FT}=991.5(\operatorname{sem} 180 \cdot 7) \mathrm{nm})$, and no potentiating effects were observed with the combination of the exercise and arginine treatments (FTA $=1275 \cdot 0$ (SEM 205.6) nM; $P<0 \cdot 001)$.

Thoracic aorta morphometry (Table 3 and Fig. 4) showed no significant changes in the IMT $(P=0 \cdot 13)$, lumen diameter $(P=0.15)$ or IMT:lumen ratio $(P=0.07)$ among the experimental groups (Table 4).

\section{Discussion}

The data presented confirm that short-term fructose overload leads to metabolic changes and to vascular damage in the longer term, as previously demonstrated by our group ${ }^{(7)}$, and these effects might culminate in the onset of CVD. The novelty of the present work is that arginine or training, either by themselves or in combination, are able to avoid the progression of CVD in its earlier stages. Aerobic training, but not arginine, is able to improve the protein content and prevent an increase in the TAG content, and both treatments, namely arginine supplementation and/or aerobic training, reversed the increases in serum insulin and adipose tissue and increased the serum NO concentration. In addition, both treatments were able to prevent the endothelial dysfunction, but no additive effects were observed.

\section{Fructose and metabolic alterations}

The association between an increase in fructose ingestion and the appearance of metabolic alterations has been previously demonstrated. Morris et al. ${ }^{(45)}$ showed that animals that received $10 \%$ fructose in water during either the day or night for 6 weeks exhibited an increase in fat mass, which corroborates the data obtained in the present study and confirms that fructose overload, even without altering the body mass, is capable of leading to alterations in body composition.

Adipose tissue is responsible for increasing the level of adipokines, which play an important role in energy homoeostasis, insulin sensitivity, immune response and vascular disease. In this context, a high ingestion of fructose is correlated with the appearance of CVD in animals ${ }^{(46)}$ and humans ${ }^{(47)}$ by increasing insulin resistance, TAG, oxidative stress and impairing vascular function $^{(7)}$, which is in agreement with the data obtained in the present study. In addition, one described mechanism for impaired endothelial function in patients with the metabolic syndrome is the decrease in NO bioavailability and fatty acid metabolism in adipose tissue, muscle and liver in health and disease $^{(48)}$. In this perspective, a high-fructose diet has been widely used in previous studies as an animal metabolic model $^{(49-51)}$, and non-pharmacological strategies for blunting the fructose-induced alterations have received increased interest.

\section{Training protocol}

The presented training protocol was effective, as demonstrated by the finding that the trained rats exhibited an increased maximal velocity capacity at the end of the 8 weeks of the training protocol. In addition, the present data show that training was able to improve the body protein content, which agrees with the literature $^{(7)}$. A previous study has shown that 8 weeks of aerobic exercise on a treadmill can prevent muscle atrophy in rats with heart failure ${ }^{(52)}$. Aerobic exercise has been recognised as an efficient preventive and therapeutic strategy for CVD because of its ability to reduce CVD risk factors ${ }^{(53,54)}$ and improve both exercise tolerance and quality of life ${ }^{(55)}$.

In contrast, arginine supplementation separately did not show an improvement in the exercise performance in this study, showed by the maintenance of the maximal running speed at the end of protocol by the fructose + arginine group. 

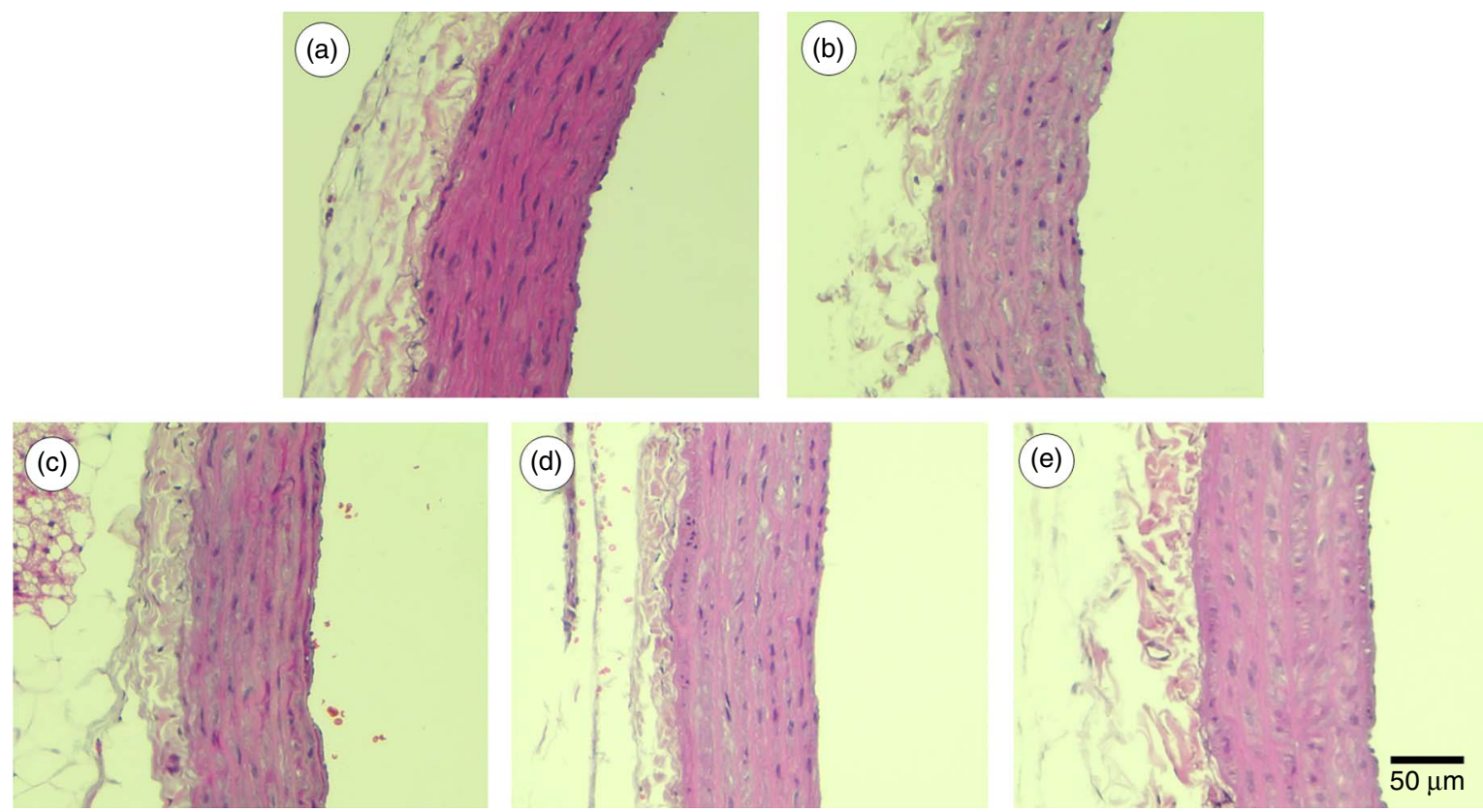

Fig. 4. Photomicrographs obtained from the thoracic aorta of control rats (a) or rats that received fructose in their drinking water (b) for 10 weeks. After 2 weeks of fructose drinking, some animals were subjected to aerobic exercise training (c), arginine supplementation (d) or the combination of both non-pharmacological treatments (e). Note that the aorta in (b) is morphologically similar to the aorta of the control group. The treatments alone or in combination did not alter the aorta morphology.

Table 4. Thoracic aorta morphometry* (Mean values with their standard errors)

\begin{tabular}{|c|c|c|c|c|c|c|c|c|c|c|c|}
\hline \multirow[b]{2}{*}{ Variables } & \multicolumn{2}{|c|}{ Control } & \multicolumn{2}{|c|}{ Fructose } & \multicolumn{2}{|c|}{ Fructose + arginine } & \multicolumn{2}{|c|}{ Fructose + training } & \multicolumn{2}{|c|}{ Fructose + training + arginine } & \multirow[b]{2}{*}{$P$} \\
\hline & Mean & SEM & Mean & SEM & Mean & SEM & Mean & SEM & Mean & SEM & \\
\hline IMT $(\mu \mathrm{m})$ & $106 \cdot 0$ & 8.58 & $104 \cdot 3$ & $1 \cdot 10$ & 98.54 & $3 \cdot 26$ & $112 \cdot 3$ & 4.02 & $110 \cdot 6$ & 3.25 & 0.41 \\
\hline Lumen diameter ( $\mu \mathrm{m})$ & 1517 & $62 \cdot 34$ & 1482 & 60.05 & $1248 \cdot 0$ & $136 \cdot 90$ & $1430 \cdot 0$ & 56.91 & 1266 & $67 \cdot 40$ & 0.20 \\
\hline IMT:Iumen ratio & 0.071 & 0.00 & 0.071 & 0.00 & 0.08 & 0.01 & 0.079 & 0.004 & 0.088 & 0.005 & 0.31 \\
\hline
\end{tabular}

IMT, intima-media thickness.

* Statistical analysis: one-way ANOVA and post hoc Student's-Newman-Keuls test.

Alvares et al. showed that $500 \mathrm{mg}$ of isolated acute arginine supplementation does not result in alterations in exercise performance when supplemented before the physical activity ${ }^{(56)}$, and Doutreleau et al. showed that 6 weeks of isolated chronic arginine supplementation is unable to alter the exercise capacity of heart failure patients ${ }^{(57)}$.

\section{Energetic ingestion and body fat mass}

The presented data show that the animals that received fructose, even under an isoenergetic diet, showed the same body mass gain as the $\mathrm{C}$ group but an increased body fat content, and this increase was reversed by isolated aerobic training and by isolated arginine supplementation, but these treatments did not exert a synergic effect. Although divergences with respect to fructose-stimulated leptin have been detected ${ }^{(58,59)}$, many studies have shown that a high fructose intake is not able to change the circulating leptin concentration ${ }^{(59,60)}$, which can explain the same energetic ingestion. However, an increase in visceral fat has been associated with the serum insulin level $^{(61-63)}$ because an increase in insulin sensibility leads to improved glucose uptake and, consequently, to increased fat deposition ${ }^{(64)}$.

Exercise practice leads to changes in body composition, and it has been elucidated that regular exercise decreases the amount of abdominal and subcutaneous fat in overweight and obese individuals, independent of the diet type ${ }^{(65)}$. It is important to emphasise that an excess of abdominal fat is a complicating factor of metabolic disorders, regardless of weight loss; thus, chronic exercise can reduce the risk of onset of, or reverse, metabolic disorders ${ }^{(66)}$.

In addition, $\mathrm{NO}$, which is increased by exercise, might stimulate the oxidation of energy substrates (including fatty acids and glucose) in adipocytes, liver, skeletal muscle, heart and the whole body ${ }^{(67)}$. According to previous studies, a decrease in fat can be achieved through an increase in the expression of PPAR $\gamma$ coactivator- $1 \alpha$, which is a regulator of oxidative phosphorylation and mitochondrial biogenesis ${ }^{(68,69)}$.

\section{Metabolic parameters}

The analysis of serum insulin revealed that fructose ingestion leads to insulin resistance with no glucose alteration, as 
previously described ${ }^{(7)}$. Both aerobic training and arginine supplementation were separately able to normalise serum insulin, but the combined treatment did not exert synergistic effects. Arginine is an amino acid involved in a number of physiological processes, and it is considered one of the most powerful secretagogues of the growth hormone ${ }^{(70)}$. It has also been described as a powerful stimulator of insulin secretion that acts directly on pancreatic $\beta$-cells ${ }^{(71)}$. In addition, it is largely accepted that regular aerobic exercise enhances insulin sensitivity. A meta-analysis showed that structured exercise training has a positive effect on HbA1c level in adults with type 2 diabetes $^{(72)}$. In addition, regular exercise improves insulin sensitivity, and this improvement might persist for $72 \mathrm{~h}$ or longer after the last training bout, even in type 2 diabetes individuals $^{(73)}$

The role of arginine in insulin resistance remains under investigation, and the published data are inconsistent ${ }^{(61,74)}$. More recent studies have shown the beneficial effects of arginine supplementation. For example, Miczke et al. ${ }^{(63)}$ showed that $20 \mathrm{~g} / \mathrm{kg}$ per $\mathrm{d}$ of arginine for $40 \mathrm{~d}$ can improve insulin resistance in rats fed a high-fat diet, and similar results have been obtained in humans ${ }^{(75)}$.

However, the training regimen alone could prevent hypertriglyceridaemia, and its combination with arginine supplementation exerted no additional effects. Chronic aerobic exercise also provides positive adaptations to the lipid profile, such as increased HDL levels and decreased levels of LDL, TAG and VLDL compared with those sedentary individuals, regardless of sex, biotype and diet. It is likely that this effect of exercise on the lipid profile occurs because of an increase in the consumption of fatty acids by muscle tissue and the activity of the lipoprotein lipase enzyme of the muscle ${ }^{(76)}$, a mechanism that is not stimulated by arginine supplementation.

\section{Vascular function}

The presented data show that arginine supplementation and aerobic training separately have the same effect on reversing vascular dysfunction, but their combination does not exert a synergic effect. Arginine, as it is largely known, is a natural substrate for nitric oxide synthesis (NOS) that, as a result of the action of eNOS and the presence of many cofactors, such as NADPH oxidase, migrates to the adjacent smooth muscle and stimulates the guanylate cyclase, resulting in an increased conversion of GTP into cGMP, which decreases the intracellular calcium concentrations and promotes the relaxation of vascular smooth muscle ${ }^{(77)}$. However, the available results for the chronic effect of arginine are conflicting. The Nitric Oxide in Peripheral Arterial Insufficiency study, which included 133 patients administered 6 months of supplementation, observed no effects on vascular reactivity ${ }^{(78)}$. In contrast, in 2009, Bai et al. ${ }^{(79)}$ published a meta-analysis of twelve studies and concluded that short-term oral L-arginine is effective at improving endothelial function.

The aerobic exercise training also increases NO production, and a 4 -week training period resulted in increases in NOS in the skeletal muscle arterioles of rats and in the vasodilatory response to acetylcholine but not in the response to sodium nitroprusside, an endothelium-independent vasodilator, suggesting an improvement in NO-dependent endothelial function ${ }^{(8)}$. However, a potentiating effect of the training and arginine supplementation treatments on endothelial function was not observed, which indicates that the training and arginine groups exhibited the same effects as the group subjected to both treatments concomitantly. These results are likely due to the ceiling effect because both treatments separately improved the similar maximum magnitude of $\mathrm{NO}$ and decreased oxidative stress ${ }^{(7,81)}$. In addition, only limited data are available for the combined treatment. Hambrecht et al. demonstrated that in patients with chronic heart failure long-term arginine supplementation and training with a submaximal handgrip exercise presented a synergistic effect on blood flow and radial artery diameter $^{(82)}$. It is important to note that this type of exercise mobilises a small muscle group and can thus show only local responses. However, to the best of our knowledge, the effect of arginine supplementation and the systemic effect of exercise have not been previously studied. It is important to emphasise that in healthy individuals the NOS enzyme activity will likely be at its maximum; thus, the enzymes exposed to L-arginine do not show improvements in activity. In individuals with a metabolic pathological condition, the NOS enzyme cannot reach its highest activity because of an increase in the intracellular concentration of NOS, resulting in decreased NO formation compared with that found under physiological conditions ${ }^{(83)}$.

In addition, the arginine paradox is largely discussed in the literature with controversial results. Wilson et al. ${ }^{(78)}$ demonstrated that arginine fails to improve endothelial function ${ }^{(78)}$. In their work, arginine supplementation decreased both the NO levels and endothelium-dependent vasodilation in individuals with peripheral arterial disease. In contrast, arginine supplementation improved the impaired endothelium-dependent vasodilation in hypercholesterolaemic animals with endothelial dysfunction ${ }^{(84)}$. Previous studies have demonstrated that reactive $\mathrm{O}_{2}$ species are associated with an impaired arginineNO pathway in individuals with metabolic alterations ${ }^{(85-88)}$. Considering the increased systemic and tissue-specific oxidative status observed in this experimental model ${ }^{(7)}$, this oxidative stress can adversely affect the action of NO and, consequently, vascular function. In contrast, arginine and aerobic training could avoid the oxidative profile caused by high fructose ingestion and could thus prevent vascular dysfunction. However, other mechanisms should be considered.

\section{Conclusion}

Thus, aerobic training is able to prevent an increase in TAG and improve the protein mass content, and both the aerobic training and arginine supplementation treatments have similar effects on preventing increases in fat content, serum insulin and serum $\mathrm{NO}$, as well as endothelial dysfunction, but do not show any additive effects.

\section{Acknowledgements}

The authors would like to thank Gustavo Mataruna da Silva for technical assistance. Also, we would like to thank the people who work at the Laboratory of Exercise Sciences. 
This work was supported by CAPES (Coordination for the Improvement of Higher Education Personnel; grant no. 473816/ 2014-8), FAPERJ (State of Rio de Janeiro Agency for Research Support; grant no. 110.310/2014) and CNPq (National Council of Scientific and Technological Development; grant no. 487.584/2013-9).

Conception and design of the experiments: R. F. M., K. J. O. and A. C. L. N.; performed the clinical experiments: R. F. M., T. G. G., T. B.-B., R. K and T. M. B. G; performed the analyses: R. F. M., N. A. V. M., F. C. B., C. F.-S. and K. J. O.; interpreted the results: R. F. M., K. J. O. and A. C. L. N.; drafted the article: R. F. M. and A. C. L. N.; edited and revised the article critically for important intellectual content and approved final version: all authors.

None of the authors has any conflicts of interest to declare.

\section{References}

1. Alwan A, Armstrong T, Cowan M, et al. (2011) WHO maps noncommunicable disease trends in all countries: country profiles on noncommunicable disease trends in 193 countries. Cent Eur J Public Health 19, 130, 138.

2. Basciano H, Federico L \& Adeli K (2005) Fructose, insulin resistance, and metabolic dyslipidemia. Nutr Metab (Lond) 2, 5 .

3. Smith SC Jr, Greenland P \& Grundy SM (2000) AHA Conference Proceedings. Prevention conference V: Beyond secondary prevention: Identifying the high-risk patient for primary prevention: executive summary. American Heart Association. Circulation 101, 111-116.

4. Eckel RH, York DA, Rossner S, et al. (2004) Prevention Conference VII: Obesity, a worldwide epidemic related to heart disease and stroke: executive summary. Circulation 110, 2968-2975.

5. Grundy SM, Garber A, Goldberg R, et al. (2002) Prevention Conference VI: Diabetes and Cardiovascular Disease: Writing Group IV: lifestyle and medical management of risk factors. Circulation 105, e153-e158.

6. Bantle JP, Swanson JE, Thomas W, et al. (1992) Metabolic effects of dietary fructose in diabetic subjects. Diabetes Care 15, 1468-1476.

7. Medeiros RF, Gaique TG, Bento-Bernardes T, et al. (2016) Aerobic training prevents oxidative profile and improves nitric oxide and vascular reactivity in rats with cardiometabolic alteration. J Appl Physiol 121, 289-298.

8. Nade VS, Kawale LA, Todmal UB, et al. (2012) Effect of bromocriptine on cardiovascular complications associated with metabolic syndrome in fructose fed rats. Indian J Pharmacol 44, 688-693.

9. Chou CL, Pang CY, Lee TJ, et al. (2013) Direct renin inhibitor prevents and ameliorates insulin resistance, aortic endothelial dysfunction and vascular remodeling in fructose-fed hypertensive rats. Hypertens Res 36, 123-128.

10. Mahmoud MF, El-Nagar M \& El-Bassossy HM (2012) Antiinflammatory effect of atorvastatin on vascular reactivity and insulin resistance in fructose fed rats. Arch Pharm Res 35, 155-162.

11. Park MH, Falconer C, Viner RM, et al. (2012) The impact of childhood obesity on morbidity and mortality in adulthood: a systematic review. Obes Rev 13, 985-1000.

12. World Health Organization (2011) Scaling Up Action Against Noncommunicable Diseases: How Much Will it Cost?. Geneva: WHO.
13. Vita JA \& Keaney JF Jr (2002) Endothelial function: a barometer for cardiovascular risk? Circulation 106, 640-642.

14. Ross R (1993) The pathogenesis of atherosclerosis: a perspective for the 1990s. Nature 362, 801-809.

15. Muiesan ML, Salvetti M, Paini A, et al. (2008) Prognostic role of flow-mediated dilatation of the brachial artery in hypertensive patients. J Hypertens 26, 1612-1618.

16. Naqvi TZ \& Hyuhn HK (2009) Cerebrovascular mental stress reactivity is impaired in hypertension. Cardiovasc Ultrasound 7, 32 .

17. Iiyama K, Nagano M, Yo Y, et al. (1996) Impaired endothelial function with essential hypertension assessed by ultrasonography. Am Heart J 132, 779-782.

18. Moncada S \& Higgs A (1993) The l-arginine-nitric oxide pathway. N Engl J Med 329, 2002-2012.

19. Cooke JP, Andon NA, Girerd XJ, et al. (1991) Arginine restores cholinergic relaxation of hypercholesterolemic rabbit thoracic aorta. Circulation 83, 1057-1062.

20. Cooke JP, Singer AH, Tsao P, et al. (1992) Antiatherogenic effects of L-arginine in the hypercholesterolemic rabbit. J Clin Invest 90, 1168-1172.

21. Bode-Boger SM, Muke J, Surdacki A, et al. (2003) Oral l-arginine improves endothelial function in healthy individuals older than 70 years. Vasc Med $\mathbf{8}, 77-81$.

22. Creager MA, Gallagher SJ, Girerd XJ, et al. (1992) L-arginine improves endothelium-dependent vasodilation in hypercholesterolemic humans. Journal Clin Invest 90, 1248-1253.

23. Gornik HL \& Creager MA (2004) Arginine and endothelial and vascular health. J Nutr 134, 2880S-2887S; discussion 2895 S.

24. Bode-Boger SM, Boger RH, Galland A, et al. (1998) L-arginineinduced vasodilation in healthy humans: pharmacokineticpharmacodynamic relationship. Br J Clin Pharmacol 46, 489-497.

25. Thompson PD, Buchner D, Pina IL, et al. (2003) Exercise and physical activity in the prevention and treatment of atherosclerotic cardiovascular disease: a statement from the Council on Clinical Cardiology (Subcommittee on Exercise, Rehabilitation, and Prevention) and the Council on Nutrition, Physical Activity, and Metabolism (Subcommittee on Physical Activity). Circulation 107, 3109-3116.

26. Fletcher GF, Balady G, Blair SN, et al. (1996) Statement on exercise: benefits and recommendations for physical activity programs for all Americans. A statement for health professionals by the Committee on Exercise and Cardiac Rehabilitation of the Council on Clinical Cardiology, American Heart Association. Circulation 94, 857-862.

27. Mann S, Beedie C \& Jimenez A (2014) Differential effects of aerobic exercise, resistance training and combined exercise modalities on cholesterol and the lipid profile: review, synthesis and recommendations. Sports Med 44, 211-221.

28. Whelton SP, Chin A, Xin X, et al. (2002) Effect of aerobic exercise on blood pressure: a meta-analysis of randomized, controlled trials. Ann Intern Med 136, 493-503.

29. Thomas DE, Elliott EJ \& Naughton GA (2006) Exercise for type 2 diabetes mellitus. The Cochrane Database of Systematic Reviews 2006, 19, CD002968.

30. Szostak J \& Laurant P (2011) The forgotten face of regular physical exercise: a 'natural' anti-atherogenic activity. Clin Sci (Lond) 121, 91-106.

31. Mora S, Cook N, Buring JE, et al. (2007) Physical activity and reduced risk of cardiovascular events: potential mediating mechanisms. Circulation 116, 2110-2118.

32. Joyner MJ \& Green DJ (2009) Exercise protects the cardiovascular system: effects beyond traditional risk factors. J Physiol 587, 5551-5558. 
33. Beere PA, Glagov S \& Zarins CK (1992) Experimental atherosclerosis at the carotid bifurcation of the cynomolgus monkey. Localization, compensatory enlargement, and the sparing effect of lowered heart rate. Arterioscler Thromb 12, $1245-1253$.

34. Forjaz CL, Tinucci T, Ortega KC, et al. (2000) Factors affecting post-exercise hypotension in normotensive and hypertensive humans. Blood Press Monit 5, 255-262.

35. Kulics JM, Collins HL \& DiCarlo SE (1999) Postexercise hypotension is mediated by reductions in sympathetic nerve activity. Am J Physiol 276, H27-H32.

36. Murias JM, Dey A, Campos OA, et al. (2013) High-intensity endurance training results in faster vessel-specific rate of vasorelaxation in type 1 diabetic rats. PLOS ONE $\mathbf{8}$, e59678.

37. Reagan-Shaw S, Nihal M \& Ahmad N (2008) Dose translation from animal to human studies revisited. FASEB J 22, 659-661.

38. Siani A, Pagano E, Iacone R, et al. (2000) Blood pressure and metabolic changes during dietary L-arginine supplementation in humans. Am J Hypertens 13, 547-551.

39. Sun L, Liu Q \& Fan J (2017) Comparison of free total amino acid Compositions and their functional classifications in 13 wild edible mushrooms. Molecules 22, 350.

40. Varnam A \& Sutherland JM (1995) Meat and Meat Products: Technology, Chemistry and Microbiology, vol. 3. Berlin: Springer.

41. Paula GS, Souza LL, Cabanelas A, et al. (2010) Female mice target deleted for the neuromedin $\mathrm{B}$ receptor have partial resistance to diet-induced obesity. J Physiol 588, 1635-1645.

42. Gomes VA, Casella-Filho A, Chagas AC, et al. (2008) Enhanced concentrations of relevant markers of nitric oxide formation after exercise training in patients with metabolic syndrome. Nitric Oxide 19, 345-350.

43. Souza LL, Cordeiro A, Oliveira LS, et al. (2011) Thyroid hormone contributes to the hypolipidemic effect of polyunsaturated fatty acids from fish oil: in vivo evidence for cross talking mechanisms. J Endocrinol 211, 65-72.

44. da Motta NA, Kummerle AE, Marostica E, et al. (2013) Antiatherogenic effects of a new thienylacylhydrazone derivative, LASSBio-788, in rats fed a hypercholesterolemic diet. J Pharmacol Sci 123, 47-57.

45. Morris M, Araujo IC, Pohlman RL, et al. (2012) Timing of fructose intake: an important regulator of adiposity. Clin Exp Pharmacol Physiol 39, 57-62.

46. Yoo S, Ahn H \& Park YK (2016) High dietary fructose intake on cardiovascular disease related parameters in growing rats. Nutrients 9, 11

47. Jin R, Welsh JA, Le NA, et al. (2014) Dietary fructose reduction improves markers of cardiovascular disease risk in HispanicAmerican adolescents with NAFLD. Nutrients 6, 3187-3201.

48. Wilkes JJ, Hevener A \& Olefsky J (2003) Chronic endothelin-1 treatment leads to insulin resistance in vivo. Diabetes 52 , 1904-1909.

49. Ibrahim MA, Amin EF, Ibrahim SA, et al. (2014) Montelukast and irbesartan ameliorate metabolic and hepatic disorders in fructose-induced metabolic syndrome in rats. EurJ Pharmacol 724, 204-210.

50. de Moura RF, Ribeiro C, de Oliveira JA, et al. (2009) Metabolic syndrome signs in Wistar rats submitted to different highfructose ingestion protocols. Br J Nutr 101, 1178-1184.

51. Kim HY, Okubo T, Juneja LR, et al. (2010) The protective role of amla (Emblica officinalis Gaertn.) against fructose-induced metabolic syndrome in a rat model. $\mathrm{Br} J$ Nutr 103, 502-512.

52. Cunha TF, Bechara LR, Bacurau AV, et al. (2017) Exercise training decreases NADPH oxidase activity and restores skeletal muscle mass in heart failure rats. J Appl Physiol 122, $817-827$.
53. Powers SK, Lennon SL, Quindry J, et al. (2002) Exercise and cardioprotection. Curr Opin Cardiol 17, 495-502.

54. Emter CA, McCune SA, Sparagna GC, et al. (2005) Lowintensity exercise training delays onset of decompensated heart failure in spontaneously hypertensive heart failure rats. Am J Physiol Heart Circ Physiol 289, H2030-H2038.

55. Roveda F, Middlekauff HR, Rondon MU, et al. (2003) The effects of exercise training on sympathetic neural activation in advanced heart failure: a randomized controlled trial. $J \mathrm{Am}$ Coll Cardiol 42, 854-860.

56. Alvares TS, Conte-Junior CA, Silva JT, et al. (2014) L-arginine does not improve biochemical and hormonal response in trained runners after 4 weeks of supplementation. Nutr Res 34, 31-39.

57. Doutreleau S, Mettauer B, Piquard F, et al. (2006) Chronic L-arginine supplementation enhances endurance exercise tolerance in heart failure patients. Int J Sports Med 27, $567-572$

58. De Angelis K, Senador DD, Mostarda C, et al. (2012) Sympathetic overactivity precedes metabolic dysfunction in a fructose model of glucose intolerance in mice. Am J Physiol Regul Integr Comp Physiol 302, R950-R957.

59. Suga A, Hirano T, Kageyama H, et al. (2000) Effects of fructose and glucose on plasma leptin, insulin, and insulin resistance in lean and VMH-lesioned obese rats. Am J Physiol Endocrinol Metab 278, E677-E683.

60. Madani Z, Louchami K, Sener A, et al. (2012) Dietary sardine protein lowers insulin resistance, leptin and TNF-alpha and beneficially affects adipose tissue oxidative stress in rats with fructose-induced metabolic syndrome. Int J Mol Med 29, 311-318.

61. Bogdanski P, Suliburska J, Grabanska K, et al. (2012) Effect of 3-month 1-arginine supplementation on insulin resistance and tumor necrosis factor activity in patients with visceral obesity. Eur Rev Med Pharmacol Sci 16, 816-823.

62. Lucotti P, Monti L, Setola E, et al. (2009) Oral L-arginine supplementation improves endothelial function and ameliorates insulin sensitivity and inflammation in cardiopathic nondiabetic patients after an aortocoronary bypass. Metabolism 58, 1270-1276.

63. Miczke A, Suliburska J, Pupek-Musialik D, et al. (2015) Effect of L-arginine supplementation on insulin resistance and serum adiponectin concentration in rats with fat diet. Int J Clin Exp Med 8, 10358-10366.

64. Matravadia S, Zabielski P, Chabowski A, et al. (2016) LA and ALA prevent glucose intolerance in obese male rats without reducing reactive lipid content, but cause tissue-specific changes in fatty acid composition. Am J Physiol Regul Integr Comp Physiol 310, R619-R630.

65. Grundy SM, Blackburn G, Higgins M, et al. (1999) Physical activity in the prevention and treatment of obesity and its comorbidities: evidence report of independent panel to assess the role of physical activity in the treatment of obesity and its comorbidities. Med Sci Sports Exer 31, 1493-1500.

66. Lakka TA \& Laaksonen DE (2007) Physical activity in prevention and treatment of the metabolic syndrome. Applied Physiol Nutr Metab 32, 76-88.

67. Fu WJ, Haynes TE, Kohli R, et al. (2005) Dietary L-arginine supplementation reduces fat mass in Zucker diabetic fatty rats. J Nutr 135, 714-721.

68. Wu Z, Puigserver P, Andersson U, et al. (1999) Mechanisms controlling mitochondrial biogenesis and respiration through the thermogenic coactivator PGC-1. Cell 98, 115-124.

69. Lehman JJ, Barger PM, Kovacs A, et al. (2000) Peroxisome proliferator-activated receptor gamma coactivator-1 promotes cardiac mitochondrial biogenesis. J Clin Invest 106, 847-856. 
70. Chromiak JA \& Antonio J (2002) Use of amino acids as growth hormone-releasing agents by athletes. Nutrition $\mathbf{1 8}, 5$.

71. Ishiyama N, Ravier MA \& Henquin JC (2006) Dual mechanism of the potentiation by glucose of insulin secretion induced by arginine and tolbutamide in mouse islets. Am J Physiol Endocrinol Metab 290, E540-E549.

72. Umpierre D, Ribeiro PA, Kramer CK, et al. (2011) Physical activity advice only or structured exercise training and association with HbA1c levels in type 2 diabetes: a systematic review and meta-analysis. JAMA 305, 1790-1799.

73. Way KL, Hackett DA, Baker MK, et al. (2016) The effect of regular exercise on insulin sensitivity in type 2 diabetes mellitus: a systematic review and meta-analysis. Diabetes Metab J 40, 253-271.

74. Kawano T, Nomura M, Nisikado A, et al. (2003) Supplementation of L-arginine improves hypertension and lipid metabolism but not insulin resistance in diabetic rats. Life Sci 73, 3017-3026.

75. Paolisso G, Tagliamonte MR, Marfella R, et al. (1997) L-arginine but not D-arginine stimulates insulin-mediated glucose uptake. Metabolism 46, 1068-1073.

76. Frayn KN, Arner P \& Yki-Jarvinen H (2006) Fatty acid metabolism in adipose tissue, muscle and liver in health and disease. Essays Biochem 42, 89-103.

77. Andrew PJ \& Mayer B (1999) Enzymatic function of nitric oxide synthases. Cardiovasc Res 43, 521-531.

78. Wilson AM, Harada R, Nair N, et al. (2007) L-arginine supplementation in peripheral arterial disease: no benefit and possible harm. Circulation 116, 188-195.

79. Bai Y, Sun L, Yang T, et al. (2009) Increase in fasting vascular endothelial function after short-term oral L-arginine is effective when baseline flow-mediated dilation is low: a meta-analysis of randomized controlled trials. Am J Clin Nutr 89, 77-84.
80. Sun D, Huang A, Koller A, et al. (1994) Short-term daily exercise activity enhances endothelial NO synthesis in skeletal muscle arterioles of rats. J App Physiol 76, 2241-2247.

81. Carvalho DS, Diniz MM, Haidar AA, et al. (2016) L-Arginine supplementation improves insulin sensitivity and beta cell function in the offspring of diabetic rats through AKT and PDX-1 activation. Eur J Pharmacol 791, 780-787.

82. Hambrecht R, Hilbrich L, Erbs S, et al. (2000) Correction of endothelial dysfunction in chronic heart failure: additional effects of exercise training and oral L-arginine supplementation. J Am Coll Cardiol 35, 706-713.

83. Tsikas D, Boger RH, Sandmann J, et al. (2000) Endogenous nitric oxide synthase inhibitors are responsible for the L-arginine paradox. FEBS Lett 478, 1-3.

84. Girerd XJ, Hirsch AT, Cooke JP, et al. (1990) L-arginine augments endothelium-dependent vasodilation in cholesterol-fed rabbits. Circ Res 67, 1301-1308.

85. Garcia VP, Rocha HN, Silva GM, et al. (2016) Exogenous 1-arginine reduces matrix metalloproteinase-2 and -9 activities and oxidative stress in patients with hypertension. Life Sci 157, 125-130.

86. Cai H \& Harrison DG (2000) Endothelial dysfunction in cardiovascular diseases: the role of oxidant stress. Circ Res $\mathbf{8 7}$, 840-844.

87. Ando K \& Fujita $T$ (2009) Metabolic syndrome and oxidative stress. Free Radic Biol Med 47, 213-218.

88. Furukawa S, Fujita T, Shimabukuro M, et al. (2004) Increased oxidative stress in obesity and its impact on metabolic syndrome. J Clin Invest 114, 1752-1761. 